\title{
The morphometric anatomy and clinical importance of the radial artery
}

\author{
W.A. Alasmari \\ Department of Anatomy, Faculty of Medicine, Umm Al-Qura University, Saudi Arabia \\ [Received: 19 September 2020; Accepted: 9 November 2020; Early publication date: 17 November 2020]
}

Background: The radial forearm flap (RFF), including the radial artery (RA) and venous components, is used for hand reconstruction surgery. Updating the knowledge of the vascular anatomy in the forearm and associated flaps, such as the RFF, is useful in bringing innovations into reconstructive surgery. This study aimed to describe the morphometric anatomy of the RA and the associated RFF in human cadavers.

Materials and methods: A total of 16 forearms from 8 human cadavers were dissected. The group consisted of 5 men and 3 women with a mean age at death of $59.05 \pm 14.06$ years. The inclusion criteria consisted of no history of trauma or surgery; thus, only apparently normal cadavers were included. The measurement of the following parameters was performed on these human cadavers: the mean diameter of the $R A$, the length of the $R A$, the average diameter of the cephalic vein, the length of the pedicle of the flap, and the average area of the radial forearm flap. Results: In males, the mean diameter of the RA at the wrist was $2.58 \pm 1.1 \mathrm{~mm}$. In females, the mean diameter of the $R A$ was $2.60 \pm 0.99 \mathrm{~mm}$, and the mean length of the $R A$ was $20.55 \pm 1.7 \mathrm{~cm}$. The average diameter of the cephalic vein was $1.8 \pm 0.8 \mathrm{~mm}$. The length of the pedicle of the flap was $8.88 \pm 1.6 \mathrm{~cm}$. The average area of the RFF was $5 \times 7 \mathrm{~cm}^{2}$.

Conclusions: This study demonstrates the morphometric anatomy of the RA and lateral forearm radial artery flaps in human cadavers, which could be useful in improving the success rate during transradial coronary interventions and performing complex hand injuries. (Folia Morphol 2021; 80, 4: 839-844)

Key words: radial artery, radial forearm flap, vascular anatomy, forearm, radial artery graft

\section{INTRODUCTION}

The radial artery (RA) is the branch of the brachial artery that arises in the cubital fossa medial to the portion of the biceps tendon and runs in front of the radial neck. The RA passes through the lateral side of the forearm and traverses below the brachioradialis muscle. In its lower third portion, the RA is situated between the tendons of the brachioradialis and the flexor carpi radialis and is located anteriorly to the radius and pronator quadratus muscle [17]. The RA descends in the intermuscular septum that is located laterally. The intermuscular septum isolates the compartments that are responsible for the flexion and extension of the forearm. Due to this separation, the

Address for correspondence: Dr. W.A. Alasmari, Department of Anatomy, Faculty of Medicine, Umm Al-Qura University, Saudi Arabia, tel: 00966597787077, e-mail: waasmari@uqu.edu.sa

This article is available in open access under Creative Common Attribution-Non-Commercial-No Derivatives 4.0 International (CC BY-NC-ND 4.0) license, allowing to download articles and share them with others as long as they credit the authors and the publisher, but without permission to change them in any way or use them commercially. 
RA is palpable towards its lower part. It enters the palm, where it is attached to the branch of the ulnar artery to form the deep palmar arch [17].

Due to its easy accessibility, the RA is useful in coronary procedures $[8,14]$. It is used in coronary artery bypass grafting ( $C A B G)$, forearm flaps, and renal dialysis by the creation of a fistula [14, 16]. The RA can be compressed easily to cause haemostasis and preliminary patient ambulation $[8,14]$. The RA graft was introduced in the 1970s as one of the alternatives to be used for CABG but was not as prevalent due to complications [1].

The RA provides blood circulation to the forearm flap by perforating vessels, which used as radial forearm flaps (RFFs) on the microsurgery [5]. Since then, many alternatives to RFFs have been innovated [5]. The radial free forearm flap is widely used for substituting soft tissue in surgeries related to head and neck cancers [5]. Veins, including the cephalic vein, accompany the RA. The cephalic vein can be included in the flap, or it can be kept as it is for RA reconstruction after harvesting the flap. It has been reported on the use of the reverse-flow radial forearm island flap, including the RA and venous components, for hand reconstruction surgery [5]. Updating the knowledge of vascular anatomy in the forearm is useful bringing innovations into the design of the radial forearm flap [18].

There are variations in the anatomy of RA, which could be found at the origin of the RA or during its course. These variations could be obstacles to different interventions, for example, diagnostic, surgical, and therapeutic interventions $[3,14]$.

Therefore, the aim of this study was to perform a morphometric analysis of the RA/RFF in human cadavers by measuring the following parameters: the mean diameter of the RA at its beginning and its end, the length of the RA, the average diameter of the cephalic vein, the length of the pedicle of the flap, and the average area of the flap. Additionally, the application of the RA graft and RFF and clinical significance for $C A B G$ and reconstructive surgery are also discussed.

\section{MATERIALS AND METHODS}

This study was conducted in the Department of Anatomy, Faculty of Medicine at Umm Al-Qura University, Makkah, Saudi Arabia. Ethical approval was obtained from the biomedical ethics commit- tee, Faculty of Medicine at Umm Al-Qura University, Makkah, Saudi Arabia. A total of 16 forearms from 8 human cadavers were considered for the dissection. The group consisted of 5 men and 3 women, who were used for the routine undergraduate teaching programme. The cadavers' mean age at death was $59.05 \pm 14.06$ years. Human cadavers with no history of trauma or surgery and without obvious vascular congenital anomalies or disease in the area under study were used; therefore, only apparently normal cadavers were included.

The surface anatomy of the structures, including the brachioradialis and flexor carpi radialis tendons in the distal part of the forearm, were documented, and the location of the RA was identified. The cephalic vein was located radially in the distal forearm.

The palmar side of the forearm was incised from wrist crease to elbow. The following parts were recognized: the flexor carpi radialis tendon, RA and its adjacent veins, palmaris longus muscle, and brachioradialis muscle. The superficial divisions of the RA and cephalic vein were identified. The external diameters of the RA and cephalic vein were observed using a digital Vernier calliper with an accuracy of $\pm 0.03 \mathrm{~mm}$ (General Tools Mfg. Co. LLC New York, NY 10013). The complete length of the RA and pedicles were measured using a metallic ruler.

The radial forearm flaps were designed, along with the template. The parts of the radial forearm flap design included the brachioradialis muscle, laterally located intermuscular septum, and cephalic vein. The medial and lateral fasciocutaneous parts of the flap, along with vessels, were raised from the distal-to-proximal side towards the lateral intermuscular septum [5].

The following parameters were estimated: the mean external diameter of the RA at its beginning and its end, the length of the RA, the average diameter of the cephalic vein, the length of the pedicle of the flap, and the average area of the radial forearm flap.

\section{Statistical analysis}

The data were statistically analysed for the means and the standard deviations.

\section{RESULTS}

Parameters associated with the RA and RFF are summarised in Table 1. The means of external diameter of RA represent the average of diameter at the 
Table 1. Parameters associated with the radial artery (RA) and the radial forearm flap (RFF)

\begin{tabular}{lccc}
\hline Parameter & Sex & $\begin{array}{c}\text { Side or } \\
\text { place }\end{array}$ & $\begin{array}{c}\text { Mean } \pm \text { stand- } \\
\text { ard deviation }\end{array}$ \\
\hline Diameter of the RA [mm] & Male & Right & $2.4 \pm 0.2$ \\
& Female & $\begin{array}{c}\text { Left } \\
\text { Right }\end{array}$ & $2.1 \pm 0.6$ \\
& & Left & $2.2 \pm 0.3$ \\
& Both male & - & $20.55 \pm 1.7$ \\
and female & & \\
& Male & - & $21.6 \pm 2.1$ \\
& Female & - & $19.5 \pm 1.8$ \\
$\begin{array}{l}\text { Average diameter of the } \\
\text { cephalic vein [mm] }\end{array}$ & - & - & $1.8 \pm 0.8$ \\
$\begin{array}{l}\text { Length of the pedicle of } \\
\text { the flap [cm] }\end{array}$ & - & - & $8.88 \pm 1.6$ \\
$\begin{array}{l}\text { Average area of the RFF } \\
\text { [cm²] }\end{array}$ & - & - & $5 \times 7$ \\
\hline
\end{tabular}

beginning and at the end of artery. In males, the mean diameter of the right RA was $2.4 \pm 0.2 \mathrm{~mm}$, the mean diameter of the left RA was $2.1 \pm 0.6 \mathrm{~mm}$. In females, the mean diameter of the right RA was $2.5 \pm 0.3 \mathrm{~mm}$, the mean diameter of the left RA was $2.2 \pm 0.5 \mathrm{~mm}$. The mean length of the RA was $20.55 \pm 1.7 \mathrm{~cm}$. The mean of RA length was $21.6 \pm 2.1 \mathrm{~cm}$ in males and $19.5 \pm 1.8 \mathrm{~cm}$ in females. The surgical anatomy of the RA and forearm flap is shown in Figure 1A and $B$. As shown in Figure 1, RA is a division of the brachial artery. It passes through the cubital fossa in front of the neck of the radius and then through the lateral side of the forearm, which traverses below the brachioradialis muscle. Surgically, this part is an area of caution, because the lateral antebrachial cutaneous nerve is located over the brachioradialis muscle, as shown in Figure $1 \mathrm{~A}$ and $\mathrm{B}$. In its lower third part, the RA is situated between the tendons of the brachioradialis and flexor carpi radialis (Fig. 1A, B) and passes anteriorly to the radius and pronator quadratus muscle (Fig. 2).

The anatomy of the RFF is shown in Figures 1 and 3. The RA supplies blood to the forearm flap. The length of the pedicle of the flap was $8.88 \pm 1.6 \mathrm{~cm}$. The average area of the RFF was $5 \times 7 \mathrm{~cm}^{2}$ (Table 1, Fig. 1A, B). The RFF is a fasciocutaneous type of flap, as septocutaneous perforators that arise from the RA supply the blood circulation. Branches of these cutaneous perforators supply blood to the skin of the lower forearm. The distant $1 / 3$ part of the forearm is
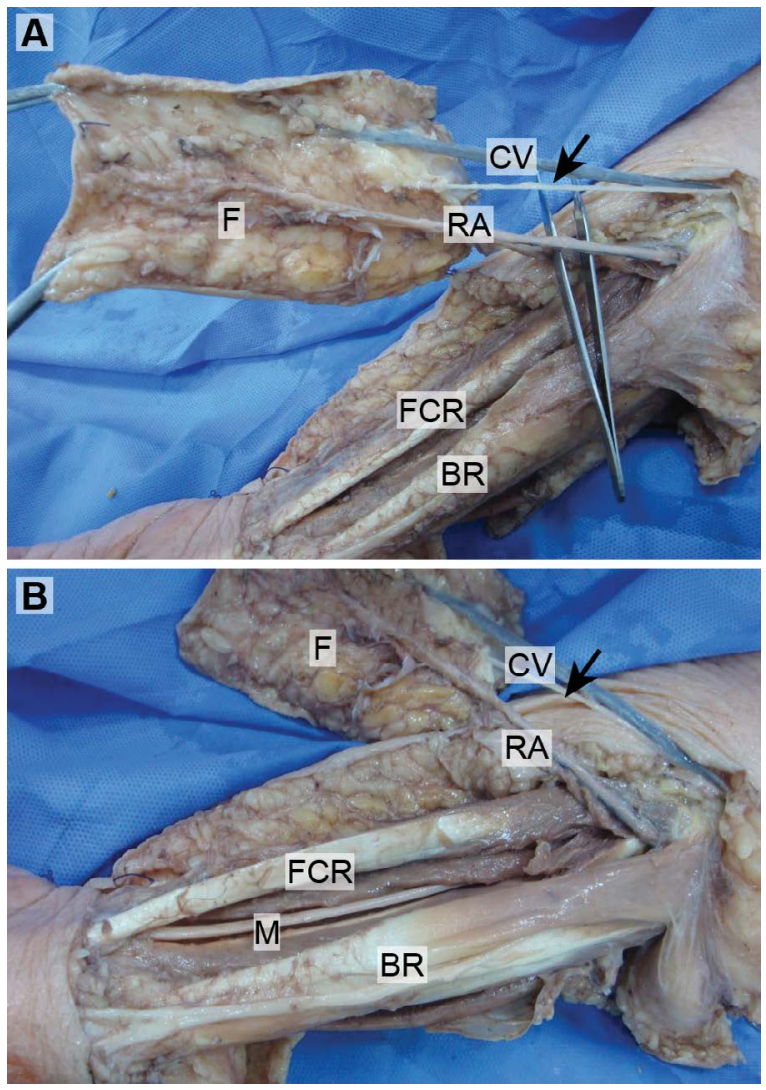

Figure 1. A, B. Surgical anatomy of the radial artery $(R A)$ and the radial forearm flap (F). The forearm radial flap (F) with the cephalic vein (CV), RA, and lateral cutaneous nerve of the forearm (arrow); FCR — flexor carpi radialis; BR — brachioradialis; $\mathrm{M}$ - median nerve.

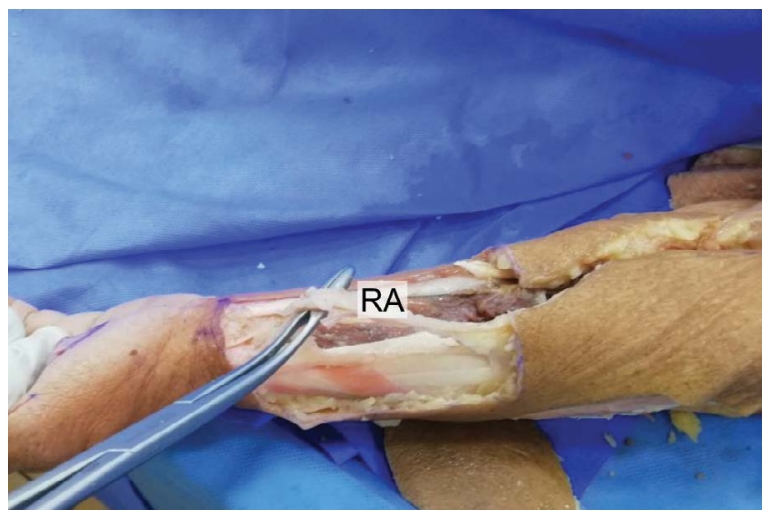

Figure 2. Anatomy of the radial artery (RA).

supplied by plenty of perforators of the RA. Perforators of the RA are shown in Figure 4.

Veins, including the subcutaneous cephalic vein, go along with the RA towards the radial side of the forearm (Fig. 1A, B). The average diameter of the cephalic vein was $1.8 \pm 0.8 \mathrm{~mm}$ (Table 1 ). 


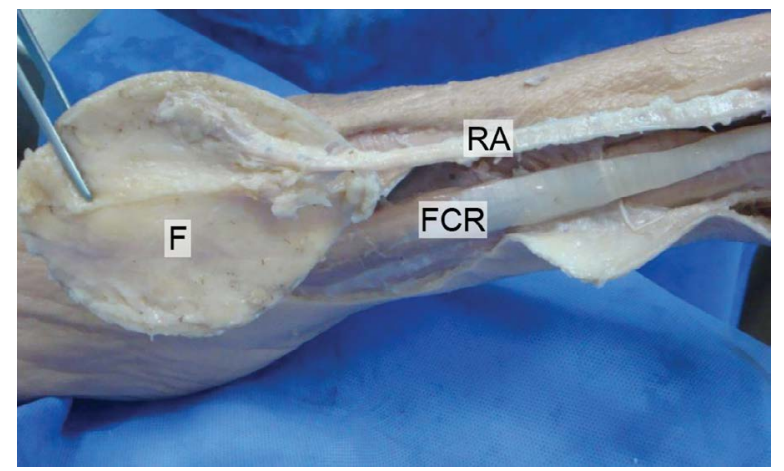

Figure 3. Anatomy of the radial artery (RA) and the dissected radial forearm flap (F); FCR — flexor carpi radialis.

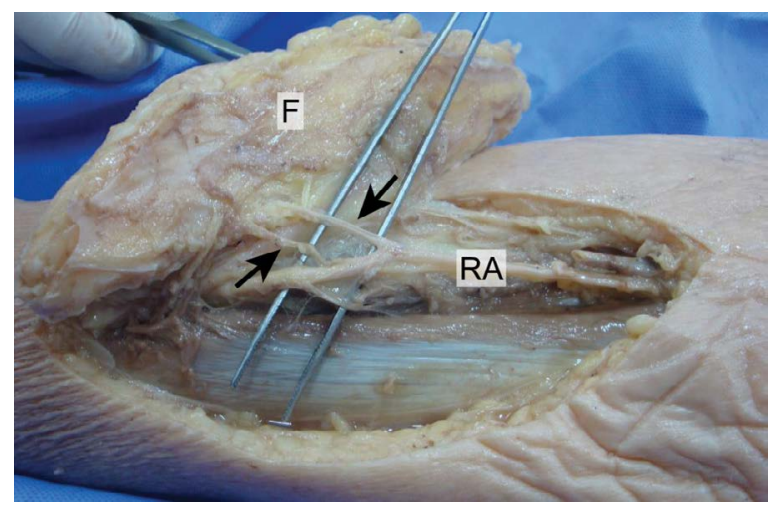

Figure 4. Perforators (arrows) of the radial artery (RA). F — raised skin flap.

\section{DISCUSSION}

Shima et al. (1996) [19] reported the mean diameter of the RA as $2.2 \mathrm{~mm}$ at the distal portions and $2.3 \mathrm{~mm}$ proximally in cadavers. Similarly, in the current study involving cadavers, in males, the mean diameter of the right RA was $2.4 \pm 0.2 \mathrm{~mm}$, the mean diameter of the left RA was $2.1 \pm 0.6 \mathrm{~mm}$, and the mean diameter of the RA at the wrist was $2.58 \pm$ $\pm 1.1 \mathrm{~mm}$. In females, the mean diameter of the right RA was $2.5 \pm 0.3 \mathrm{~mm}$, the mean diameter of the left RA was $2.2 \pm 0.5 \mathrm{~mm}$, and the mean diameter of the RA at the wrist was $2.60 \pm 0.99 \mathrm{~mm}$. However, in a study conducted by Nasr [14], the external diameter of the RA was $3.2-3.3 \mathrm{~mm}$ in men and women at $1 \mathrm{~cm}$ distal to its origin and $3.0-3.1 \mathrm{~mm}$ in men and women at $2 \mathrm{~cm}$ closer to the styloid process of the radius. A reason for these discrepancies could be related to the race of the cadavers used in the studies. The mean diameter of the RA seems to be different in live patients than that in cadavers based on various studies $[2,19,24,25]$. Human cadavers are treated with formalin that may result in damage to tissues and differences in the diameters of the RA of living humans and cadavers. The internal diameter of the artery demonstrates the volume of blood flow to the tissue more significantly than the external diameter of the artery. It is important to know the RA diameter to improve the success rate during transradial coronary interventions. For coronary interventional procedures, using the RA appears to be a preferable option than transfemoral or transbrachial approaches due to easier haemostasis and unimportant veins or nerves around the RA and the presence of perforators $[1-3,5,14,16,18,19,21,24,25]$.

In the present study, the mean length of the RA was $20.55 \pm 1.7 \mathrm{~cm}$. This finding was closer to that $(20-24 \mathrm{~cm})$ observed in previous studies conducted by Nasr [14] and Guo [9].

Radial artery grafts are more suitable for vessels with a higher degree of injury, such as CABG [7]. In a study conducted by Desai et al. (2004) [7] of 440 patients, RA grafts were related to fewer incidences of graft occlusion at one year compared to saphenous-vein grafts. Several studies have indicated that the RA is an advantageous option over the saphenous vein for grafting due to the following aspects: higher patency, easier harvest, lack of modification of blood circulation in the arm following removal of the graft, longer-lasting outcomes, fewer complications, and lesser impact on ischaemic reperfusion/ischaemia at rest and exercise in postoperative forearm blood flow at the donor site $[1,17]$. However, harvesting the RA may rarely cause claudication of the hand, and patients should be informed about this possibility.

In a study conducted on a total of 34 cases of hand reconstruction surgery, the range of the flap (containing the skin island flap and adipofascial pedicle flap) was 9-18 cm, and the width and length of the adipofascial pedicle were $3-4 \mathrm{~cm}$ and $3-5 \mathrm{~cm}$, respectively [5]. This was a study in relation to live human cases. However, in the present cadaveric study, the length of the pedicle of the flap was $8.88 \mathrm{~cm}$, and the average area of the RFF was $5 \times 7 \mathrm{~cm}^{2}$. The RFF in the current study was centralized over the subcutaneous cephalic vein, which might be included in the flap, or it might be used for RA reconstruction after the flap is harvested. Moreover, throughout the elevation of the flap in this study, the lateral cutaneous nerve of the forearm was preserved in the flap to form a flap with sensations. This nerve is located in the plane superficial to the deep fascia. Generally, any portion 
from the proximal to the distal section of the radial forearm can be used for the flap, as the RA supplies blood to the entire skin of the forearm and hand through perforators [5]. However, the distant $1 / 3$ part of the forearm is supplied by plenty of perforators of the RA [5, 11, 12]. Kimura et al. (2017) [12] reported that the average number of cutaneous perforators for the RA was $9.03 \pm 2.28$ per forearm, and $2.29 \mathrm{~cm}$ was the mean distance between adjacent perforators of the RA. The number of perforators from the RA was greater than that from the ulnar artery. However, Hekner et al. (2016) [11] observed the distal segment of the forearm and found that the number of relevant perforators was not different between the radial and ulnar arteries.

The components of the fasciocutaneous flap are the underlying skin, fascia, and vascular pedicle. For many years, the RFF has been used commonly in plastic surgery [13]. It is used as a substitute for skin and the mucosa underneath. It is extremely pliable at the place where the skin is extremely damaged. Its skin islands, vascularized tendon, and bone (osteocutaneous flap) make it a multipurpose viable flap [5].

A free flap RFF is mainly used in head and neck surgery [20]. Fasciocutaneous RFF from the distal part is an appropriate option for hand reconstruction [5]. The reverse pedicle containing RFF is a widely recognized alternative option for treating dorsal hand wounds [23]. Primarily, a reverse pedicle containing RFF and rarely a free RFF is used for the reformation of the mutilated hand or complex hand injuries [4, 20,22].

Sometimes, if the flap is elevated in the distal part of the limb, a large superficial vein causes venous congestion, excessive accumulation of blood that needs to be drained, and hampered function of the flap [6]. In such cases, ligation of the superficial vein at the distal part is helpful. Distally located forearm flaps, including the deeper important artery, have been widely used for hand and wrist reformation. A forearm flap with an intact deep important artery at the distal base is useful for hand and wrist rebuilding [5].

This reverse pedicled flap is useful, safe, and effective in hand rebuilding when it contains thin, easily transplantable, and realistic skin with optimum blood circulation. However, there are two major drawbacks of the reverse pedicled flap at the donor site. First, if the main artery is not used, then it affects the functionality of the flap. Second, a deformed scar is formed if a split skin graft is used during the closure of the flap [5]. In the reverse pedicle flap, it is impor- tant to keep the RA intact, as it is a prominent artery in the distal part of the forearm, and this artery is an important source of blood circulation $[5,10,15]$.

\section{CONCLUSIONS}

In summary, this study demonstrates the morphometric measurements of the RA/RFF in human cadavers. It is important to know the diameter, length, and other features of the RA to improve the success rate during transradial coronary interventions. The RA is an advantageous option versus the saphenous vein for CABG. A radial forearm flap is mainly used for the reformation of the mutilated hand or complex hand injuries. Therefore, updating knowledge of the vascular anatomy in the forearm and associated flaps, such as the RA/RFF, is useful for better diagnostic, therapeutic, and surgical interventions.

\section{Acknowledgements}

Thanks to Prof. Wagih Elbarrany for his valuable help during the experimental work and photographing.

\section{Conflict of interest: None declared}

\section{REFERENCES}

1. Al-Sabti HA, Al Kindi A, Al-Rasadi K, et al. Saphenous vein graft vs. radial artery graft searching for the best second coronary artery bypass graft. J Saudi Heart Assoc. 2013; 25(4): 247-254, doi: 10.1016/j.jsha.2013.06.001, indexed in Pubmed: 24198449.

2. Ashraf T, Panhwar Z, Habib S, et al. Size of radial and ulnar artery in local population. J Pak Med Assoc. 2010; 60(10): 817-819, indexed in Pubmed: 21381609.

3. Bidarkotimath S, Avadhani R, Kumar A. An anatomical study of primary pattern of arteries of upper limb with relevance to their variations. J Health Allied Sci NU. 2020; 02(01): 08-14, doi: 10.1055/s-0040-1703547.

4. Chang J, Jones NF. The mutilated hand. 2005, doi: 10.1016/ b978-1-56053-446-4.x5001-1.

5. Chang SM, Hou CL, Zhang F, et al. Distally based radial forearm flap with preservation of the radial artery: anatomic, experimental, and clinical studies. Microsurgery. 2003; 23(4): 328-337, doi: 10.1002/micr.10155, indexed in Pubmed: 12942523.

6. Chang SM, Hou CL. Role of large superficial veins in distally based flaps of the extremities. Plast Reconstr Surg. 2000; 106(1): 230-231, doi: 10.1097/00006534-20000700000060, indexed in Pubmed: 10883652.

7. Desai ND, Miwa S, Kodama D, et al. A randomized comparison of radial-artery and saphenous-vein coronary bypass grafts. N Engl J Med. 2004; 351(22): 2302-2309, doi: 10.1056/NEJMoa040982, indexed in Pubmed: 15564545.

8. Franchi E, Marino P, Biondi-Zoccai GG, et al. Transradial versus transfemoral approach for percutaneous coronary proce- 
dures. Curr Cardiol Rep. 2009; 11(5): 391-397, doi: 10.1007/ s11886-009-0054-4, indexed in Pubmed: 19709500.

9. Guo W. Arterial grafting for coronary artery bypass surgery. Heidelberg, Springer, Berlin 2006.

10. Haerle M, Häfner HM, Dietz K, et al. Vascular dominance in the forearm. Plast Reconstr Surg. 2003; 111(6): 1891-1898, doi: 10.1097/01.PRS.0000057529.76413.D7, indexed in Pubmed: 12711949.

11. Hekner DD, Roeling TAP, Van Cann EM. Perforator anatomy of the radial forearm free flap versus the ulnar forearm free flap for head and neck reconstruction. Int J Oral Maxillofac Surg. 2016; 45(8): 955-959, doi: 10.1016/j. ijom.2016.03.003, indexed in Pubmed: 27012603.

12. Kimura T, Ebisudani S, Osugi I, et al. Anatomical Analysis of Cutaneous Perforator Distribution in the Forearm. Plast Reconstr Surg Glob Open. 2017; 5(10): e1550, doi: 10.1097/ GOX.0000000000001550, indexed in Pubmed: 29184752.

13. Masquelet AC. Anatomy of the radial forearm flap. Anat Clin. 1984; 6(3): 171-176, doi: 10.1007/BF01784310, indexed in Pubmed: 6394038.

14. Nasr AY. The radial artery and its variations: anatomical study and clinical implications. Folia Morphol. 2012; 71(4): 252-262, indexed in Pubmed: 23197145.

15. Riekkinen $\mathrm{H}$, Karkola $\mathrm{K}$, Kankainen $\mathrm{A}$. The radial artery is larger than the ulnar. Ann Thorac Surg. 2003; 75(3): 882-884, doi: 10.1016/s0003-4975(02)04557-5.

16. Rodríguez-Niedenführ $M$, Vázquez $T$, Nearn $L$, et al. Variations of the arterial pattern in the upper limb revisited: a morphological and statistical study, with a review of the literature. J Anat. 2001; 199(Pt 5): 547-566, doi: 10.1046/j.14697580.2001.19950547.x, indexed in Pubmed: 11760886.

17. Sajja LR, Mannam G, Pantula NR, et al. Role of radial artery graft in coronary artery bypass grafting. Ann Thorac Surg. 2005; 79(6): 2180-2188, doi: 10.1016/j. athoracsur.2004.07.049, indexed in Pubmed: 15919345.
18. Sham E, Masia JA, Reddy TJ. Vascular analysis of radial artery perforator flaps. Ann Maxillofac Surg. 2018; 8(1): 66-72, doi: 10.4103/ams.ams 1 18, indexed in Pubmed: 29963427.

19. Shima H, Ohno K, Michi Ki, et al. An anatomical study on the forearm vascular system. J Cranio-Maxillofac Surg. 1996; 24(5): 293-299, doi: 10.1016/s10105182(96)80062-x.

20. Soutar DS. In Flaps and Reconstructive Surgery. 2009. https://www.us.elsevierhealth.com/flaps-and-reconstructive-surgery-9780323243223.html.

21. Valsecchi O, Vassileva A, Musumeci G, et al. Failure of transradial approach during coronary interventions: anatomic considerations. Catheter Cardiovasc Interv. 2006; 67(6): 870-878, doi: 10.1002/ccd.20732, indexed in Pubmed: 16649233.

22. Wang SJ, Teknos TN, Chepeha DB. Complications in Head and Neck Surgery. 2009, doi: 10.1016/b978-1-4160-42204.x5001-9.

23. White $C P$, Steve AK, Buchel EW, et al. Reverse radial artery flap perforator anatomy and clinical applications. Ann Plast Surg. 2016; 77(3): 345-349, doi: 10.1097/SAP.0000000000000551, indexed in Pubmed: 26678105.

24. Yokoyama N, Takeshita S, Ochiai M, et al. Anatomic variations of the radial artery in patients undergoing transradial coronary intervention. Catheter Cardiovasc Interv. 2000; 49(4): 357-362, doi: 10.1002/(sici)1522726x(200004)49:4<357::aid-ccd1>3.0.co;2-z, indexed in Pubmed: 10751755.

25. Yoo BS, Yoon J, Ko JY, et al. Anatomical consideration of the radial artery for transradial coronary procedures: arterial diameter, branching anomaly and vessel tortuosity. Int J Cardiol. 2005; 101(3): 421-427, doi: 10.1016/j. ijcard.2004.03.061, indexed in Pubmed: 15907410. 